\title{
Redemocratização e imprensa no Brasil Contemporâneo: a Folha de S. Paulo e o Jornal do Brasil no final do regime
}

\section{militar}

\section{Ian Pereira Alves ${ }^{1}$}

\section{Resumo}

O presente estudo tem como objetivo analisar a cobertura da grande imprensa nacional sobre alguns pontos a respeito da transição democrática brasileira - período que se estende de 1974, com a posse do general-presidente Ernesto Geisel, até 1985 com a eleição pelo Colégio Eleitoral do primeiro presidente civil desde o Golpe de 1964. Nesse sentido, procura-se perpassar as complexas relações entre imprensa, regime militar e sociedade civil, com a finalidade de compreender como diferentes sujeitos articularamse política e ideologicamente neste momento singular da história brasileira.

Palavras-chave: Imprensa; Regime Militar; Brasil; Transição Democrática.

\section{Abstract}

This paper aims to analyse the coverage of the national press on some points of the Brazilian democratic transition - the period that ranges from 1974, with the inauguration of the general-president Ernesto Geisel, to 1985 with the election by the Electoral College of the first civil president since the military coup of 1964. Thus, the focus is to go through complex relationship between press, military regime and civil society, aspiring to understand how different subjects articulated politically and ideologically in this singular time of Brazilian history.

Keywords: Press; Military Regime; Brazil; Democratic Transition.

\section{Introdução}

Adentramos ao estudo da fase final da ditadura militar no Brasil (1974-1985) com o objetivo de reconstruir as diferentes perspectivas e projetos acerca do futuro do país e, ao mesmo tempo, analisar o papel da grande imprensa - Folha de São Paulo (FSP) e Jornal do Brasil (JB) - no suporte ou crítica a esses projetos. De fato, nesse período esteve em voga discussões acerca da distensão democrática, bem como suas características, ritmos e alcances — tendo tanto os militares, com sua distensão "lenta, gradual e segura", quanto a oposição criado um projeto ${ }^{2}$ próprio que possuía pretensões de ser o "legítimo" ou "verdadeiro".

\footnotetext{
${ }^{1}$ Graduando em História pela Universidade Federal de Goiás, bolsista no Programa Institucional de Bolsas de Iniciação Científica (PIBIC). Goiânia, GO. E-mail: ianpalves0@gmail.com

${ }^{2}$ Utilizamos a expressão por simples convenção, tendo em vista que a mesma se consolidou na historiografia corrente sobre o período da abertura democrática brasileira. Na verdade, tais "projetos", por não possuírem um corpus discursivo elaborado nem a coesão que a palavra reclama, possivelmente seriam melhores definidos
} 
Desse modo, compreendemos que as ideias acerca da abertura democrática foram primeiramente concebidas no âmbito militar, mas não se restringiram a ele, tendo extrapolado à sociedade civil, principalmente em sua fase final. Portanto, à grande imprensa reserva-se papel fundamental nesse debate, pois muitas vezes ela serviu de polo de discussões ${ }^{3}$, ou seja, campo fértil para articulação e debate desses projetos distintos (Cruz, 1996).

\section{Pressupostos teóricos e metodológicos}

Naturalmente, devemos esclarecer nossa abordagem frente a esse enigmático objeto, pois tão múltiplo quanto as páginas dos periódicos são as possibilidades de interpretação dos mesmos. Foi de extrema importância para a constituição deste trabalho as perspectivas de Cruz e Peixoto. Em linhas gerais, as autoras argumentam que a imprensa deve ser encarada mais como um "ingrediente" do processo histórico, ou seja, um "agente ativo", do que um reflexo da realidade ou mero banco de dados (Cruz \& Peixoto, 2007). Desse modo, então, podemos encontrar uma abordagem alternativa tanto à desconfiança frente à imprensa — presente por conta de seu caráter subjetivo - quanto à sua incorporação acrítica. Na perspectiva das autoras, não existe testemunho inocente, não obstante sua plataforma de elaboração e divulgação. Portanto, é necessário historicizar qualquer fonte (seja ela escrita ou não), isto é, entender seus processos de elaboração e divulgação, bem como os sujeitos presentes e partícipes dos mesmos.

De fato, todo discurso, qualquer que seja, sempre remete, mesmo que indiretamente, a questões e intencionalidades típicas de uma época, ou em outras palavras: a seu imaginário. Concordarmos com Bronislaw Braczko (1985), filósofo e historiador polonês, quando postula que tal esfera não é secundária; assim como o êxito na dominação simbólica não se faz como mero "adorno ou "complemento" em relação à dominação "real”, mas funciona como um duplo reforço. Através de uma estrutura simbólica e representativa, o imaginário interfere em muitos setores da vida coletiva. Ele funciona duplamente como: a) uma forma pela qual a comunidade interpreta a realidade, gerando uma identidade própria e também para o outro, portanto delimitando as relações de cada sociedade internamente e externamente, como também com a natureza e o espaço; b) informando acerca do real, fornece também orientação, modelando os comportamentos e/ou mobilizando a ação coletiva. Portanto, dentro do imaginário de cada

\footnotetext{
através de outro termo. De fato, tais sujeitos do período - incluindo tanto os militares quanto os grupos de oposição - mais do que um projeto com suas estratégias, sentidos e objetivos bem definidos, experienciaram um momento de indefinição política em que os sentidos da abertura eram discutidos através de diferentes "horizontes de expectativa". Sobre este conceito, ver: Koselleck (2006).

${ }^{3}$ A autora enfatiza como a imprensa periódica transforma-se, pelo menos em São Paulo, em principal expressão da cultura escrita, tornando-se, logo, fonte e foco de articulação de processos culturais, práticas e discursos.
} 
sociedade está imbricado, por meio de símbolos e signos, uma representação da ordem social — com todas as hierarquias e posições marcadas - podendo ser manejada pelo poder para a manutenção e efetivação do mesmo (Baczko, 1985).

Contudo, o poder não se efetiva de maneira planificada e absoluta, enfrentando sempre percalços proporcionados pelos demais agentes sociais, os quais não constituem os grupos dominantes. Raymond Williams (1979), em sua obra Marxismo e Literatura, esboça um esquema geral sobre como as práticas hegemônicas funcionam no interior de uma cultura. Em primeiro lugar, o autor quebra uma dualidade recorrentemente empregada - que interpreta a cultura como dominação ou geração espontânea - quando esse complexo conceito é utilizado. Para ele, a cultura não é apenas geração espontânea, podendo sofrer pressões externas. Contudo, não se identifica simplesmente como dominação, sendo fundamentalmente um processo gerador de modos de vida, ou seja, uma prática criativa situada no limiar entre as pressões e os limites de ação. Em outras palavras, Williams abre espaço para considerarmos a atuação dos sujeitos na produção do novo. Desse modo, além do que é dominante existe também o residual e o emergente, estando cada um desses elementos em constante movimento e relação.

Com efeito, o residual é tudo aquilo que foi significativo em algum momento do passado e que, efetivamente, incorporou-se ao presente, ou seja: é um vestígio do passado que encontra função no presente - mesmo que se altere a sua posição dentro dos processos culturais — não apenas servindo como uma espécie de souvenir ou memória explícita. Nesse sentido, apresenta natureza diversa em relação ao arcaico, pois este último é também um elemento do passado, mas é entendido e resgatado como tal, enquanto o residual, por estar totalmente atrelado à cultura dominante, é percebido sendo uma característica do próprio presente.

Por emergente, por outro lado, dizemos ser tudo aquilo que surge dos novos processos históricos e culturais. Contudo, não se define apenas pelo estigma do "novo", mas também através da forma que se relaciona com o dominante: podendo ser de oposição, portanto, indo de encontro aos valores, buscando sua substituição, alteração ou diluição; ou alternativo, buscando simplesmente uma outra opção à ordem estabelecida, sem necessariamente lutar contra a mesma.

Posto isso, é da relação dessas três esferas, do seu imbricamento — como também do seu atrito - que surge a hegemonia. Portanto, por conta da própria dinâmica humana, nunca é uma construção estática, mas está sempre se alterando de acordo com a complexificação da vida social. 
Certamente, seria incoerente pensar essas categorias de Williams como absolutas, ou mesmo como "gavetas" prontas para guardar a realidade social. Contudo, podem ser de grande valor se utilizadas como indicadores de direção básica, direção essa que a realidade da própria pesquisa termina por mostrar.

Adicionalmente, o conceito de "horizonte de expectativa" de Koselleck (2006) encontrou papel central dentro de nossa análise. $\mathrm{O}$ autor desenvolve um esquema representativo circular, em que o presente - lugar onde encontra-se ação humana - está no limiar das experiências passadas e projeções para o futuro, ou seja, entre o que o historiador denomina "espaço de experiência" e "horizonte de expectativa". Desse modo, os indivíduos orientam-se tanto pelo conhecimento disponível do passado (sendo este muitas vezes reconstruído e moldado de acordo com as necessidades e intencionalidades presentes em dado momento histórico) quanto pela antecipação do que ainda não aconteceu (Koselleck, 2006).

Com base nesses referenciais teóricos, propomos uma metodologia que consistirá na análise crítica dos periódicos, desde a reconstituição de sua história anterior até seu papel durante o recorte proposto - com ênfase nos períodos decisivos para as reformas do Pacote de Abril $^{4}$ e as campanhas Diretas Já!. Identificamos relações entre os jornais e os distintos projetos para a distensão democrática. Em outras palavras, existindo numa mesma conjuntura tanto as intenções militares quanto da oposição — dividida entre o MDB (Movimento Democrático Brasileiro), partido de oposição oficial admitido pelo regime; e os movimentos sociais, defensores de uma democracia mais direta - almejamos captar qual teria sido a orientação da grande imprensa na administração de todos esses projetos. Teria ela pactuado com algum deles? Ou antes, constituído projetos próprios?

São questões ainda pouco elucidadas pela historiografia, pois o foco de análise entre essa relação regime-imprensa encontra-se, essencialmente, nos primeiros anos posteriores a ditadura e, sobretudo, após o AI-5. Além do mais, é de extrema valia o esclarecimento a respeito dessa parte da história de nosso país, principalmente em tempos em que a polarização e radicalização política - muitas vezes atreladas e/ou respaldadas por recuperações e (re)construções equivocadas acerca tanto do Golpe de 1964 quanto da Ditadura Militar - causam temor. Nesse sentido, torna-se pertinente o conselho de Francisco Silva Teixeira: é necessária a reflexão sobre as bases em que se assentaram a ditadura, bem como suas condições de exercício, para

\footnotetext{
${ }^{4}$ Foi batizado como "Pacote de Abril" o conjunto de leis reformistas impostas pelo general-presidente em 1977. Tais reformas previam, a grosso modo, o retorno das eleições indiretas para governadores e de um terço dos senadores. Adicionalmente, tinham por objetivo estender a Lei Falcão — que previa uma restrição da propaganda política como uma tentativa de frear a crescente popularidade do partido de oposição MDB — para as eleições estaduais e federais (Reis, 2014).
} 
impedir que a instrumentalização do esquecimento seja usada como arma contra a nossa frágil democracia (Silva, 2003).

\section{Distensão "lenta, gradual e segura" e os desarranjos com a oposição: o imprevisto e o improvável no processo de abertura democrática}

Como afirmado anteriormente, a devolução do poder aos civis foi gestada inicialmente dentro do próprio seio militar. Conhecendo o fato de que o regime não era eternamente sustentável, julgavam necessário realizar a transição. Contudo, tal perspectiva de abertura democrática deveria obedecer estritamente a uma série de exigências. Sob o argumento de evitar a instabilidade política e o radicalismo, era almejada uma distensão "lenta, gradual e segura", devendo tal processo ser realizado durante o governo Geisel, sucessor de Médici. Tinham por finalidade, aproveitando o milagre brasileiro, ${ }^{5}$ institucionalizar o regime, mas ao mesmo tempo conservar certas mudanças realizadas e evitar o revanchismo.

Contudo, a oposição — majoritariamente articulada através do MDB — possuía tanto percepções próprias sobre a conjuntura daquele momento quanto objetivos distintos para o futuro, como expressa claramente a candidatura de Ulysses Guimarães e Barbosa Lima Sobrinho à presidência da república, nas eleições de $1974^{6}$. De fato, questionavam a natureza e o ritmo imposto pelos militares à distensão (Fico, 2015). É importante lembrarmos que tal discordância não era trivial, pois, desde a sucessão do governo Médici, o MDB ia valendo-se progressivamente de uma imagem positiva. Adicionalmente, tanto a conjuntura internacional — especialmente o turning point na política norte-americana, com a eleição de Jimmy Carter - quanto o contexto interno - a crise econômica, que começou a ser sentida de forma mais expressiva após $1975^{7}$ — contribuíram para a dissolução das bases nas quais se assentava o regime (Silva, 2003). Desse modo, os militares iam perdendo paulatinamente a dianteira do processo de abertura, abrindo espaço para a oposição formal do MDB e para a oposição das ruas, que iam, principalmente após 1978, conquistando espaço no âmbito político.

\footnotetext{
${ }^{5}$ É interessante destacar o imaginário construído em torno do "Brasil Potência" - espécie de percepção, muito ligada a projetos desenvolvimentistas que indicavam que o país era ou estaria destinado a se tornar uma potência - sobretudo nos anos de eficiência econômica do governo Médici. Tal construto apontou em direção a uma ideia de abertura democrática conduzida pelos militares durante o tempo em que ainda conservavam certas bases de aceitação. Para a discussão mais detalhada sobre o "milagre brasileiro", ver: Prado \& Earp (2003).

${ }^{6} \mathrm{O}$ fato de haver eleições formais não deve ser interpretado como parte de um caráter menos autoritário da ditadura brasileira. Na verdade, a sucessão de generais serve para afastar o personalismo e dar certa aparência de normalidade.

${ }^{7}$ Contudo, é importante destacar que não foi a crise que estimulou a abertura, mas a eficiência econômica. De fato, atingindo proporções cada vez maiores, a crise interferiu no ritmo do processo e levou a opinião pública a se voltar contra o regime militar (Silva, 2003).
} 
É precisamente Eder Sader, em seu livro Quando Novos Personagens Entram em Cena, publicado em 1988, quem identifica e imprime a esses movimentos sociais de caráter popular uma projeção de democracia. É possível perceber como inseriram novos atores no cenário político, ampliando assim o espaço de ação e reivindicação de indivíduos oriundos de setores sociais geralmente excluídos. Portanto, ocorre a criação de um novo sujeito, essencialmente coletivo, ou seja: há uma projeção de democracia latente nesses movimentos, ao estabelecer um novo tipo de sociabilidade associativa e solidária. Esse projeto, em relação ao pertencente ao dos militares, apresenta um corpus discursivo menos elaborado, mas se expressa pela mobilização dos indivíduos a partir de objetivos que são definidos pela própria vida cotidiana. Portanto, mais que a preocupação com o "jogo político" do alto, como é o caso do MDB, esses grupos estão preocupados com reivindicações diretas que influenciarão em suas vidas práticas. É exatamente por conta desse caráter singular que se torna tão difícil definir uma espécie de agenda política para esses movimentos. Contudo, é evidente seu ímpeto de mobilização movido pelo desejo de uma democracia construída através de uma participação mais direta dos sujeitos no espaço político.

Evidentemente, é impossível esgotar toda a diversidade de práticas e orientações presentes no período através dessa divisão esquemática. Mesmo entre os próprios militares havia fissuras e cisões políticas. Não obstante o ímpeto do regime em tentar mostrar-se como um corpo sólido e coerente em todos seus membros, havia divergências internas tanto na abordagem a ser empregada contra a oposição quanto nos objetivos futuros para o país. O projeto de Golbery Couto e Silva - ideólogo da devolução do poder aos civis, em termos estabelecidos pelos militares - , por exemplo, enfrentava resistência também das forças mais conservadoras do regime (Reis, 2014).

Em suma, o que esteve em jogo durante o processo de abertura política era, paralelamente: o alcance e o ritmo da distensão, como também quem efetivamente a realizaria. De fato, os militares obtiveram sucesso em conduzi-la na sua primeira fase, mas durante o governo Figueiredo a iniciativa passaria para a sociedade civil. Obviamente, essas disputas desenvolveram-se de forma bastante violenta, em muitos momentos. Há, por parte do governo, sempre presente a tentativa de recuperar o pioneirismo do processo, algo que se expressa, por exemplo, na repressão tanto no governo Geisel quanto no de Figueiredo. Contudo, sobretudo na década de 1980, após o ressurgimento dos trabalhadores no cenário político, o processo de transição democrática estaria para sempre afetado pelo "imprevisto e o improvável”, ou seja, 
teria que ser somada a intervenção dos trabalhadores no processo que, a priori, estava sendo conduzido sem eles (Reis, 2014).

\section{Trajetória dos jornais}

Antes de partir propriamente para a análise dos periódicos é necessário, pelo menos em linhas gerais, explicitar alguns pontos da trajetória de cada um dos jornais abordados. Suas histórias, através de cooperações e tensões, auxiliam no esclarecimento dessa ambígua relação entre a imprensa e o regime.

Em primeiro lugar, é pertinente destacar que a maioria dos jornais apoiou o golpe civil$\operatorname{militar}^{8}$ de 1964. Na verdade, muitos setores da sociedade civil, estando entre estes a imprensa, reconheciam-se como parte da "revolução" - como chamaram o golpe, em um primeiro momento - e queriam influenciar em seus objetivos e direcionar seus rumos. Adicionalmente, fatores econômicos contribuíram para a cumplicidade entre a ditadura e os jornais, não sendo, então, coincidência o fato de que houve uma forte modernização da imprensa durante o regime. De fato, os militares financiaram muitas empresas de notícias, pois seus maiores anunciantes eram órgãos do Estado (Dias, 2011).

Evidentemente, com o fim da censura e a derrocada do AI-5, em 1978, os jornais começaram a contrapor-se de forma mais evidente ao governo ditatorial. Contudo, como veremos mais especificamente na trajetória do JB e da FSP, esse movimento não é linear, constituindo-se mais por uma dinâmica oscilatória entre crítica e apoio, palavra e silêncio.

Tratando-se especificamente do periódico paulista, é importante destacar a gestão Frias, a partir da década de 1960. Nesse momento ocorre a constituição da FSP como principal jornal do grupo fragmentado da Folha. Tal gestão, que enfrentou graves problemas econômicos, preocupou-se muito mais com a faceta empresarial do jornal. Isso contribuiu em grande parte para o apoio do jornal tanto ao Golpe de 1964 quanto à ditadura em suas fases iniciais, pois o jornal não possuía meios de "caminhar com as próprias pernas" e necessitava da ajuda financeira estatal — não sendo, portanto, mera coincidência o fato de que o maior enriquecimento da empresa se deu justamente durante os anos de chumbo (Dias, 2011).

Contudo, é necessário advertir quanto a simplificação que nos acometeria se simplesmente realçássemos os motivos econômicos. De fato, por serem jornais liberais, os objetivos tanto da FSP quanto do JB, pelo menos por um momento, alinharam-se aos dos militares. Assim, tais veículos de comunicação repreendiam as "ideias radicais" oriundas dos

\footnotetext{
${ }^{8}$ Para a discussão sobre o caráter civil do Golpe e implicações de nomenclatura ver: Fico (2014).
} 
comunistas e trabalharam conjuntamente com outros agentes, das forças armadas e da sociedade civil, na desestabilização do governo de João Goulart. A FSP, como observado por Rodrigo Patto Sá Motta, trabalhou até mesmo para a construção de uma imagem positiva de Castelo Branco. O autor mostra como foi publicado pelo jornal diversas "caricaturas simpáticas" ao general presidente, interpretando seu governo como comprometido com os verdadeiros valores liberais e afastado da ala radical do regime (Motta, 2013).

Em comparação ao JB, podemos dizer que a FSP agiu de forma muito mais tímida em relação ao governo quando os primeiros excessos autoritários começaram a revelar-se. O primeiro mostrou-se presente em críticas pontuais, principalmente em relação à pauta da liberdade de expressão que se tornou cada vez mais restrita com o amadurecimento do regime. De fato, houve uma diminuição do apoio aos militares, mas nunca um confronto direto, uma oposição mais expressiva, por parte da Folha. Pelo menos não até 1975: neste momento, já sob a direção de Cláudio Abramo, o jornal finalmente tinha alcançado sua independência financeira, podendo assumir uma postura mais crítica em relação à ditadura.

A trajetória do JB, por outro lado, é muito mais inusitada. Com efeito, em sua fundação, realizada por Dantas e Nabuco ainda durante os períodos iniciais da Primeira República, em 1891, constituiu-se num jornal com forte caráter monarquista. Teceram fortes críticas aos simpatizantes do novo tipo de governo. Contudo, com a compra por parte de um grupo ligado a Rui Barbosa e, consequentemente, com o controle de sua direção, o foco editorial deslocouse da crítica à república como um todo para apenas parte dela. Nesse momento argumentavase em defender a "verdadeira república", esta que, segundo o jornal, havia sido corrompida por Floriano Peixoto (Ferreira, 2008).

O que de fato nos interessa não é, no entanto, saber pelos pormenores das figuras que estiveram por trás da direção ou os proprietários do JB. Fundamentalmente, é necessário compreender como, durante sua trajetória peculiar, o jornal passou por duas linhas básicas distintas: a primeira constituía um polo de debates políticos e culturais; ao passo que a segunda esteve mais relacionada aos interesses locais e comerciais. Desse modo, como afirma Ferreira:

Assim, sucederam-se as diferentes fases: a do grande órgão de opinião e contestação ao regime republicano; a do "Popularíssimo", como era pejorativamente chamado; a do jornal moderado que valorizava as colunas literárias e artísticas animadas por membros da Academia Brasileira de Letras, e finalmente a do "boletim de anúncios". Paralelamente, também se alternavam fases de crise e estabilidade financeira (Ferreira, 2008). 
Durante os anos 1950, o JB passou por um processo de transformação, uma reforma. Havia uma atmosfera geral de mudança, mas o caminho a seguir ainda estava por definir-se. Mais importante para nossa análise é o fato de que, durante todos esses processos, o JB jamais perdeu o seu caráter de jornal liberal-conservador (Ferreira, 2008).

Como já afirmado, o JB teve uma postura muito mais ousada frente ao regime do que a $\mathrm{FSP}^{9}$ - pelo menos até 1975 - tecendo críticas pontuais, driblando a censura através do trabalho dos chargistas, mesmo após o AI-5. Contudo, por seu caráter fragmentado e casual, tal oposição não deve ser sobrevalorizada. Como reforçado por Motta, houve certa acomodação dos jornais ao regime militar, ou seja, se não o apoiaram totalmente - como ocorreu nos períodos que imediatamente sucederam ao golpe — também não lhe fizeram oposição de frente, adaptando-se e sobrevivendo à ditadura (Motta, 2013).

Tendo em mente esse percurso percorrido por ambos os jornais, cheio de acidentes e desvios, nosso objetivo é compreender como se orientaram no período da transição democrática. Não bastaria imprimir uma unidade ou identidade ideológica fixa aos periódicos e, a partir daí, criar assertivas claras, pois como vimos estes jornais são, antes de tudo, empresas preocupadas com questões, muitas vezes, bem materiais - como a captação de leitores e mesmo o risco de falência.

\section{A transição democrática nos termos da Folha de S. Paulo e do Jornal do Brasil: 0 Pacote de Abril e a campanha Diretas Já!}

Por meio das publicações da FSP, podemos ter uma pista de como o jornal se articulou perspectivas distintas de abertura democrática, de cujas noções aproximaram-se e afastaramse, de acordo com o momento. No ano de 1977, contrariando as falas acerca da entrega do poder aos civis, Geisel experimentou, com o Pacote de Abril, um verdadeiro "surto ditatorial" (REIS, 2014). Em 14 de abril, um dia após o conjunto de leis reformistas ser outorgado, o jornal apresenta uma posição crítica às intenções e ações promovidas pelo poder Executivo.

Por isso que a inclusão de temas nem políticos nem institucionais na primeira parte do pacote, juntamente com a reforma do Judiciário, causa perplexidade e inevitavelmente conduz a interpretações dos motivos oficiais que de forma alguma se coadunam com a imagem que o presidente Geisel tem procurado construir até agora. Ao conceber, com a mão esquerda, duvidosas benesses, enquanto com a mão direita desce

\footnotetext{
${ }^{9}$ Esta, inclusive, publicou elogios e uma charge amigável para receber o presidente-general Médici (Motta, 2013, p. 81)
} 
a vara de marmelo, o Governo nos induz a que se vejam nesse ato propósitos demagógicos, que lembram inevitavelmente as práticas habituais dos idos do Estado Novo. [...]. Não é destruindo a imagem e o prestígio de instituições como o Congresso e o processo democrático que se ajuda a construir uma nação desenvolvida e forte. E essa destruição, uma vez iniciada, pode conduzir a destinos que ninguém é capaz de prever (Folha de São Paulo, Um Estranho, 1977, P. 2).

$\mathrm{Na}$ perspectiva do periódico, as ações do governo ferem o processo democrático ao desferir um golpe contra a autonomia do congresso nacional. Mesmo as ações tomadas sob a justificativa de uma necessidade urgente na resolução de problemas concretos - como a questão das férias dos trabalhadores e o inquilinato — são entendidas aqui como atos "demagógicos", ou seja, que exercem o autoritarismo sob a justificativa de uma suposta preocupação com os problemas que angustiam os setores populares. Mais interessante ainda, dentro da mesma problemática, é a vinculação das ações do governo ao passado do Estado Novo. Evidentemente, os governos militares, desde o Golpe de 1964, sempre tentaram afastar o personalismo existente no período de Vargas de sua própria imagem. ${ }^{10}$

De fato, neste momento, a ditadura já precisava lidar com a dissolução de suas bases de apoio. O objetivo do governo em imprimir os ritmos e alcances da distensão não permaneceu intocado pelas reivindicações da oposição. Em boa parte, por conta deste dado, houve sempre um esforço do governo em fazer-se pioneiro da distensão. Desse modo, como é possível perceber através da crítica feita no que se refere às instituições democráticas, a FSP se insere em meio a esse grupo tão diverso dos críticos ao regime nesse momento: denuncia a incapacidade do governo em atingir a democracia, talvez sendo cético mesmo da sua disposição para tal empreitada.

O fato de que o periódico criticou o governo é suficiente para amalgamá-lo em meio a oposição, ao lado do MDB e dos outros grupos? Como veremos, a realidade político-social do período é muito complexa. Por mais que possamos definir estes grupos sob a legenda vaga e imprecisa de "oposição", conforme adentramos ao nosso objeto de estudo, as fissuras entre diferentes grupos tornam-se cada vez mais pronunciadas.

Em meio aos periódicos, encontramos críticas severas ao $\mathrm{MDB}$, denunciando sua insuficiência em fazer oposição forte ao regime. Segundo o periódico, o partido não era muito

\footnotetext{
${ }^{10}$ Tal preocupação se expressa, por exemplo, na dificuldade encontrada por Otávio Costa durante sua gestão na Aerp (Assessoria Especial de Relações Públicas). Muitos militares viam com maus olhos a criação de qualquer órgão que pudesse remeter ao "fantasma do DIP (Departamento de Imprensa e Propaganda) de Getúlio Vargas". Para discussão mais detalhada, consultar: Fico(2003).
} 
melhor que o seu rival, a Arena, pois não possuía a capacidade de inovar-se, não podendo jamais constituir um rival confiável pelo eleitorado:

A mediocridade que marca o desempenho político do MDB se deve basicamente ao horror de suas sucessivas lideranças em retirar de cima da legenda a canga da transitoriedade sob a qual foi formada, com a Arena, pelo Ato Institucional número 2. [...]. O MDB - tanto quanto sua irmã siamesa, a Arena - não inova, apesar das aparências (Folha de São Paulo, Ser, 1977, p. 2).

É extremamente curiosa essa crítica realizada pela Folha ao MDB, indicando o seu desgaste, justamente pelo momento preciso em que foi feita: o partido, como já citado, experimentou progressivamente os efeitos de uma boa imagem na opinião pública. Levemos em conta, por exemplo, que o ano de 1974 marca uma vitória da oposição nas urnas (Reis, 2014).

Entrementes, para o jornal, o crescimento do eleitorado do MDB devia-se muito mais ao esgotamento da ditadura do que à eficiência da legenda oposicionista. Logo, sob essa perspectiva, o partido de oposição não possuía eleitores fiéis, mas apenas indivíduos cansados do regime que não possuíam outra opção de voto. Desse modo, para a FSP, tanto o partido do governo quanto seu principal opositor direto não possuíam os requisitos necessários para realizar a transição democrática que o país necessitava.

E o que pensava a FSP, então, em relação aos crescentes movimentos populares? Seriam eles os agentes preferidos para realizar a abertura política do regime? De fato, desde o final da década de 1970 - mais especificamente em 1978, com a greve dos operários — os trabalhadores $^{11}$ inseriram-se cada vez mais no espaço político, expressando, por meio de pressões e reivindicações, suas perspectivas para a abertura democrática (Munakata, 1980).

A FSP, principalmente na década de 1980, esforçou-se em se apresentar como um jornal preocupado com a reivindicação popular. Por conta da sua grande divulgação e apoio à campanha Diretas já!, o periódico ficou positivamente conhecido como o "jornal das diretas". Contudo, essa relação não é tão simples e, evidentemente, como já explorado por alguns autores $^{12}$, comporta intenções e dissimulações. De fato, nesse período é possível notar um

\footnotetext{
${ }^{11}$ Evidentemente, os trabalhadores não constituíram um grupo totalmente coeso e homogêneo, tendo fomentado, muitas vezes, disputas internas. Para as cisões dentro da classe trabalhadora, assim como os detalhes da luta sindical, sobretudo nos anos 1980, consultar: Santana, (2003).

${ }^{12}$ De acordo com Pires (2008), essa imagem positiva que a Folha tentou elaborar de si própria foi contestada, sobretudo nos anos 2000, quando tanto a produção acadêmica — destacando-se os trabalhos de Maria Aparecida de Aquino e Anne-Marie Smith — quanto o trabalho de jornalistas — dentre eles Edgar Olímpio, Hamilton Octavio de Souza e Vasco Oscar Nunes - começou ponderar as ambíguas conexões entre a empresa e o regime.
} 
esforço do jornal em expressar pautas populares, denunciando, por exemplo, os problemas econômicos que pesavam sobre boa parte da população. Contudo, o diário nunca deixou de ser liberal. De fato, usou essa roupagem de luta democrática para granjear leitores, diferenciandose do seu principal concorrente, O Estado de S. Paulo, de forte caráter conservador (Arbex 2001).

Elaine Muniz Pires (2008) demonstra como a Folha se proveitou das pautas dos movimentos sociais para constituir-se como uma empresa de sucesso e emergir das campanhas Diretas já! como um jornal "democrático" e preocupado com o leitor. A autora analisa também a relação entre a Folha da Tarde (FT), reinventada pela empresa em 1967, e o regime, submetendo ambos - jornal e contexto político - a um exame maior, levando em conta também a FSP e o grupo Folha como um todo. As relações entre a FT e o regime eram muito estreitas, levando em consideração, por exemplo, o fato da grande presença de militares ${ }^{13}$ no jornal vespertino, após o AI-5 (Pires, 2008).

As críticas ao "Pacote de Abril", portanto, não representam, necessariamente, uma adesão do periódico ao "projeto popular" de democracia, mas de uma utilização dessa imagem para atingir fins próprios, como adaptar-se aos novos tempos de abertura democrática. Exatamente por ser liberal, as críticas da FSP se restringiram, em grande medida, ao aspecto políticoinstitucional dos problemas que acometiam o país. Em outras palavras, o periódico reproduz a defesa clássica da igualdade jurídica, tão cara aos liberais, mas em momento algum se mostra preocupado com a igualdade social. Mesmo os problemas econômicos que direcionavam boa parte da população à miséria, sob essa perspectiva, eram creditados à má administração do aparelho estatal. $\mathrm{O}$ jornal não passou perto sequer de uma crítica às relações entre as corporações (sendo ele próprio uma delas), o governo e os problemas sociais. Mesmo na pauta das eleições diretas, tão presente na FSP, a preocupação residia apenas em conceder o voto formal, mas nunca se estendia às implicações do ato de votar em uma sociedade como a brasileira dos anos 1980 - ignorava os assédios que o eleitor sofria em função de seu voto e o alcance e significado do mesmo.

Contudo, diferentemente de Pires, não consideramos tais evidências como suficientes para afirmar que a FSP aprovou o projeto de distensão militar. Agir com intenção de "seduzir" 14

\footnotetext{
${ }^{13}$ Nos períodos da ditadura o jornal Folha da Tarde ficou conhecido como o de maior "tiragem", trocadilho que expressa uma crítica aos militares que constituíam sua redação. De fato, como reflete a autora, funcionários da polícia federal trabalhavam nas redações como repórteres e editores (Pires, 2008).

${ }^{14}$ Arbex constata a associação feita pelo próprio Otávio Frias Filho, diretor da Folha de S. Paulo, ao personagem Drácula, no artigo "Vampiros de papel”. Como o vampiro na relação com suas vítimas, o jornal usaria a estratégia de "seduzir" o leitor. Para mais detalhes, ver: Arbex (2001).
} 
o leitor, distanciando-se assim das lutas sociais populares não a aproxima automaticamente ao conteúdo discursivo dos militares. Como demonstrado neste trabalho, os periódicos não sugerem tal correspondência. Entretanto, concordamos com a autora, ao mostrar, tanto através da leitura e interpretação de historiografia acadêmica, reportagens jornalísticas e entrevistas, que a imagem positiva construída pelo jornal é fruto muito mais das suas preocupações como empresa do que qualquer inclinação "verdadeiramente democrática" e que o papel do jornal Folha da Tarde complexifica a questão ${ }^{15}$. Há uma contradição aparente nesses dois polos de defesa distintos constituídos pela FT e FSP, sendo o primeiro muito mais sensível às questões militares enquanto o segundo muito mais crítico, sobretudo a partir da década de 1975.

Podemos resolver essa questão observando o já citado caráter empresarial do jornal: a constituição de duas linhas ideológicas distintas para seus jornais indica que o grupo Folha se preocupava em se manter e resistir ao momento de agitação política no Brasil. Nesse contexto, ser fiel, escolhendo apenas um lado nessa disputa, poderia ser extremamente danoso caso o lado escolhido perdesse. Ou seja, tal contexto explica-se tanto pela preocupação em vender jornais quanto pela dificuldade do momento, por conta da sua indeterminação, em fornecer direções políticas claras para os sujeitos se posicionarem. Desse modo, seria extremamente vantajoso para a Folha da Tarde, e consequentemente para o grupo Folha como um todo, manter as "portas abertas" com o governo - tanto por conta de possíveis recursos de publicidade quanto pela questão da censura que era operada de forma diferente em relação a outros jornais, tendo o Folha da Tarde contado com uma liberdade de divulgação de notícias muito maior durante o regime militar. ${ }^{16}$

Assim como a FSP, o JB também teceu críticas pesadas ao casuísmo das reformas do ano de 1977 que, realizadas pelo presidente Geisel e não o congresso, buscavam favorecer o partido do governo nas próximas eleições, já que o mesmo havia sofrido um duro golpe nas urnas, em 1974. O jornal insere-se também nessa esteira de críticos ao regime, agora de forma bem mais evidente que nos anos 1960.

As reformas políticas concebidas pelo Executivo na medida de suas necessidades prementes passam agora ao teste da realidade social [...] Será inevitável que nossos politicamente desgastados e eleitoralmente

\footnotetext{
${ }^{15}$ Pires conduz uma análise que demonstra como o jornal serviu como divulgador das notícias pela perspectiva oficial do governo - publicando mesmo casos de mortes que ainda não haviam se efetivado, quando os sujeitos se encontravam ainda mantidos presos pelo governo, como é o célebre caso de Joaquim Seixas, preso em 1971 (Pires, 2008).

${ }^{16}$ O próprio Aggio Jr. - diretor do Folha da Tarde após o AI-5 - afirmava não haver censura no jornal porque simplesmente não era necessário. Era permitido noticiar, diferentemente de outros jornais, por exemplo, "ações de grupos armados, sequestros e mortes" (Pires, 2008).
} 
vazios queiram aproveitar a garantia de uma vitória sem méritos porque certa [...]. Fica suficientemente claro que em todas essas acomodações de interesses e necessidade do regime faltou uma visão que visasse a premiar varões ilustres e capazes de suportar no ombro o peso de uma restauração do prestígio do congresso [...]. A vontade de prevenir situações críticas de natureza inconstitucional pode ser mais criativa do que o exercício de uma mentalidade casuística, que procedeu como um arauto sombrio as reformas de que se querem servir alguns nomes sem votos e sem credibilidade política (Jornal do Brasil, Casuísmo, 1977, p. $8)$.

Apesar de coincidir com a FSP, portanto, na crítica ao pacote de reformas, o JB evidencia de forma mais clara o aspecto das distintas esferas políticas. Para o periódico, as reformas são absurdas por consistir em uma atitude desesperada de um grupo — o dos apoiadores da ditadura —, o qual já com todas suas bases de apoio diluídas, ainda tenta firmar-se no poder. Além do mais, são negativas por não considerar uma reestruturação do congresso, ou seja, por perpetuar a primazia do executivo em relação ao poder legislativo.

Ao sucessor do presidente Figueiredo tocará a missão de compatibilizar os dois conceitos da Revolução de março, para recompor a ordem constitucional destruída e dar condições de equilíbrio ao funcionamento dos Poderes. A nação anseia por encerrar os ciclos das crises e não perdoará aos que ocupam hoje a cena política, no Governo como na Oposição, se falharem na indicação do caminho que leve à estabilidade das instituições. A abertura atual é apenas um meio para colocar à vista a democracia (Jornal do Brasil, Conflito, 1984, p. 8).

Para o JB, a questão central não se definia fundamentalmente pela escolha de qual grupo conduziria a transição democrática, mas essencialmente em suas formas e natureza. Se preocupava com a restituição do equilíbrio entre os três poderes, abalado por conta da hipertrofia do executivo. Contudo, como expresso pelo próprio jornal, tal realização seria muito improvável por parte do governo central, pois o mesmo insistia em ações de caráter autoritário - como a censura, pauta sempre presente nas páginas do periódico.

O JB se percebia dentro do grupo diverso que promoveu a "Revolução de março", como indica a própria continuidade do uso do termo. Como já afirmado, muitos setores da sociedade civil que ajudaram a dar o Golpe de 1964 se consideravam legítimos para interferir nos rumos e sentidos do que chamaram de "Revolução". A crítica, portanto, se estende ao centralismo promovido pelos governos militares, em que muitos desses setores ficaram de fora da tomada de decisões. O que importa aqui não é se a articulação entre o passado e o presente feita pelo JB é precisa, assim como o fato de sua crítica ser justa ou não, mas realçar a próprio resgate da memória de 1964 e a sua importância dentro da leitura feita pelo jornal para gerar o julgamento 
sobre a realidade da abertura democrática. Ou seja, eles entendiam que o regime não estava mais pretensamente "moralizando" a política e, portanto, suas ações autoritárias não teriam mais legitimidade, como no passado (pós-1964) teria tido. Ao invés disso, o "Pacote de Abril" visava justamente o estabelecimento de regras arbitrárias para as eleições, incorrendo no reforço às práticas que o regime havia sido, na visão do periódico, instituído para combater.

A preocupação do JB cobre muito mais a política institucional, em detrimento das reivindicações populares. Apesar de encontrarmos presentes em suas páginas denúncias de desaparecimentos políticos e da severidade da polícia (Silva, 1983), o JB se apresenta ainda mais distante dos movimentos sociais que a FSP. No contexto das Diretas, por exemplo, o jornal mostrou-se a favor da sua realização, contudo, o foco nunca esteve na reivindicação popular, mas no caráter negociativo do congresso e em sua autonomia para tomar a decisão de liberar o voto direto para presidente da república.

As reais garantias para o Congresso decidir soberana e livremente estão na sociedade [...]. A decisão do Congresso terá de ser acatada e respeitada porque os brasileiros querem viver na democracia [...]. Não é, portanto, apenas a decisão sobre uma emenda que o Congresso vai assumir. Está implícita a nova responsabilidade de conduzir daqui em diante o país segundo a vontade política nele representada. Não haverá, de forma alguma, qualquer frustração que se materialize em forma de insensatez por parte da sociedade. [...]. A ameaça da frustração social, brandida pelos oradores oposicionistas para intimidar a maioria, não passa de retórica de comício [...]. Equivalem-se, portanto, no sentido de refletir resíduos de radicalismo, mas se anulam como peças inadequadas ao momento histórico (Jornal do Brasil, Dia, 1984, p. 10).

Tal texto nos permite apreender como o JB se articulava político-ideologicamente naquele período, às vésperas da votação da emenda Dante de Oliveira, que visava ao restabelecimento das eleições diretas para presidente da república, direito suprimido pela ditadura. Em primeiro lugar, como já afirmado, o jornal ressalta enfaticamente a legitimidade do congresso na definição dos novos rumos políticos para a nação — não como o único agente político participante no debate, mas como o único que possui a primazia de resolução.

Para o periódico a população poderia até se expressar, "reivindicar, protestar, exigir", como assinalado pelo redator do jornal, Félix de Athayde, em seu texto Povo: fenômeno novo (Athayde, 1984, p. 11). Contudo, a posição do JB é restritiva: “ a Oposição aprendeu, ou precisa aprender, que decisões como a de quarta-feira [referência a votação da emenda Dante de Oliveira, realizada em 25/04/1984] não se tomam na rua, mas no foro próprio que é o poder legislativo" (Jornal do Brasil, Eloqüencia, 1984, p. 10). Desse modo, condiciona a população a uma posição passiva em relação a qualquer decisão advinda de seus "representantes", negando- 
lhe o direito de agir politicamente e de fazer pressão sobre os parlamentares, exercendo, assim, sua cidadania.

Após a derrota da emenda Dante de Oliveira, o periódico chegou a elogiar a população por sua "maturidade" e "conduta exemplar" frente a decisão tomada pelo legislativo, pelo fato de que não houve nenhuma "perturbação da ordem" (Jornal do Brasil, Sinal, 1984, p. 10). Em outras palavras, para o JB a política ocorre prioritariamente no "alto", ou seja, nos ambientes institucionais e oficiais. As mobilizações de massa que extrapolam essa esfera são frequentemente identificadas com radicalismo indesejado e até mesmo incoerente à conjuntura política. O periódico defende a negociação, mas realizada fundamentalmente pelos indivíduos presentes na política padronizada tradicional, sem romper com seus rígidos limites.

A respeito das greves de 1978, por exemplo, a atenção dada pelo JB é muito menor do que normalmente se esperaria para um movimento de tal magnitude — que começou com os operários do $\mathrm{ABC}$ paulista, mas que depois se estendeu para outras regiões e categorias de trabalhadores. Poucas referências aos trabalhadores e às greves são encontradas em seus editoriais, que demonstram preocupação muito maior a outros eventos da política nacional e internacional.

Tal postura é também decorrente de sua linha liberal, de defesa inconteste do capital privado, como fica patente na ocasião em que o JB tratou de um projeto de lei que previa uma alteração da Consolidação das Leis do Trabalho (CLT) em relação às férias dos trabalhadores - regulamentando o padrão de 30 dias corridos e a possibilidade de venda de parte desse período, contanto que fossem resguardados intocáveis 10 dias para descanso - o jornal argumenta que tal ato é fruto de uma mentalidade essencialmente paternalista:

Pode ocorrer uma distorção, já fartamente conhecida: uma legislação trabalhista impulsionada por forte sentimento assistencialista, gerado por ímpetos de indiscutível paternalismo. [...]. A distribuição de benefícios deve ter como objetivo a preservação de um equilíbrio entre empregados e empregadores: os prêmios concedidos a um não podem penalizar ao outro. [...] E, no momento, não se deve menosprezar alguns obstáculos à rentabilidade das empresas brasileiras. É altíssima a carga tributária; são onerosos os custos financeiros [...] (Jornal do Brasil, Paternalismo, 1978, p. 10).

Fica evidente, após essas linhas, para onde o JB deslocou a problemática: em pleno estalar das greves em busca de melhores condições de trabalho e salários mais justos o periódico faz alusão ao "equilíbrio" entre empregados e patrões, como se a própria ligação entre estes sujeitos não tivesse como pressuposto também uma relação de poder - porque o patronato possui os meios de produção enquanto o trabalhador operário possui apenas sua força de trabalho, sendo 
portanto o lado mais vulnerável desse jogo de forças - que tende-se favorável ao lado do patrão. Desse modo, faz a defesa aos interesses das empresas privadas, preocupado com suas condições de existência e manutenção de lucros, bem como seu desenvolvimento à parte das "mãos" do Estado.

É de chamar a atenção, no entanto, como o JB constrói sua opinião em relação a greve dos professores, no Rio de Janeiro, ainda em 1978, acusando o movimento como portador de caráter ilegal e radical. A posição do jornal é, de todo modo, extremamente severa:

O que se discute [...] deplora e repudia — é a forma escolhida para fazer valer as exigências. [...] os professores estão prejudicando conscientemente toda uma comunidade como não tem como defenderse dessa agressão. [...]. Não são bons professores, nem serão bons brasileiros, os líderes desse reprovável espetáculo de ilegalidade e radicalismo (Jornal do Brasil, Greve, 1978, p. 10).

Na visão do periódico, a causa da luta por melhores condições de trabalho dos profissionais da educação poderia até ser justa, no entanto, a greve torna-se uma irresponsabilidade por causar supostos transtornos ao contexto urbano e pelos docentes, supostamente, se negarem a apertar "a mão que o Governo estendia em sentido construtivo e reconciliador" - tendo então os grevistas promovido um movimento de "tumultuada assembleia”, mas “destituído de motivações políticas” (Jornal do Brasil, Greve, 1978, p. 10). Desse modo, o JB reforça sua escolha pela política institucional e oficial como meio legítimo de transformação da sociedade em detrimento das mobilizações realizadas por trabalhadores.

Nas páginas da FSP os operários do $\mathrm{ABC}$ paulista receberam um respaldo mais significativo, em parte por estarem ambos — jornal e movimento social — presentes no mesmo estado. O periódico publicou, em 13 de março de 1978, uma matéria evidenciando os anseios dos grevistas e sua "posição contra o dissídio" (Folha de São Paulo, Posição, 1978, p. 9) acertada em assembleia geral no dia anterior. Pouco tempo depois, a respeito do clima de tensão que envolveu o ambiente paulista naquele período, a postura do jornal é ainda mais interessante:

São Paulo, portanto, não é um caldeirão prestes a explodir, como acaba de afirmar o senador Magalhães Pinto. [...]. Falar, reunir-se, clamar e reclamar são maneiras de aliviar a carga de tensão social exercida sobre o Poder. Não é tudo, é claro, pois só a correspondência a esses reclamos poderá acabar com esse processo de efervescência. É aqui que se deve esperar dos homens do Poder a compreensão e humildade suficientes para o fenômeno da crescente movimentação que se sente em São Paulo. [...] A força de trabalho [...] contém energia bastante para provocar a abertura de um processo de reivindicação e de debate [...] (Folha de São Paulo, Panela, 1978, p. 2). 
O jornal identifica nos líderes políticos a responsabilidade de negociação com as reivindicações desses atores sociais que emergem dos movimentos dos trabalhadores paulistas - concedendo mais legitimidade ao movimento que o JB - considerando sua eventual incapacidade de realizar tal tarefa como o que possivelmente poderia aumentar a tensão e, consequentemente, explodir a "pequena válvula existente", ou seja, gerar o caos. Logo, é possível para a população reivindicar e se expressar em seus anseios e objetivos, mas a primazia de ação encontra-se sempre nas instituições políticas oficiais.

Devemos concordar com Munakata (1980), ao afirmar que os crescentes movimentos dos trabalhadores não foram noticiados com o justo corpo e coesão que se esperaria - em uma análise que, não obstante as particularidades presentes em cada seção do movimento grevista, fundamentasse seu caráter unitário na reivindicação por melhores salários e condições de vida. Não é feita por exemplo, uma articulação pelo JB entre os movimentos paulistas e as greves de professores no Rio de Janeiro, uma vez que nenhuma influência é citada.

Portanto, fica evidente que, dentro dessa conjuntura, marcada pela incerteza e indefinição que constitui o momento de transição democrática, ambos os periódicos adotaram perspectivas distintas de acordo com suas próprias definições de "democracia" e de "sociedade". Contudo, a evidência não é suficiente para dizer que os jornais aderiram a qualquer um dos "projetos" de democracia, seja do governo ou das oposições. Tanto a FSP quanto o JB realizaram um recuo frente a esses distintos horizontes de expectativas e dialogaram com seus objetivos, selecionando elementos dentro de um critério próprio, para o favorecimento das pautas que lhe eram mais caras. No caso da FSP, articulou-se uma pauta favorável à oposição popular tanto por conta da sua intransigente defesa ao voto direto quanto pela preocupação em validar sua imagem como um jornal preocupado com os anseios populares. O JB, em contrapartida, estava disposto a se relacionar com as ideias tanto do governo quanto da oposição, desde que o equilíbrio entre os poderes oficialmente instituídos e a liberdade de expressão jornalística fossem respeitados.

\section{A perspectiva de Tancredo Neves como primeiro presidente civil desde o Golpe de 1964}

Por conta dessas particularidades, logo, os periódicos também ofereceriam perspectivas distintas de interpretação da escolha, de forma indireta, de Tancredo Neves como próximo presidente da república. No caso da FSP, é evidente a decepção em relação ao fracasso das Diretas, tendo uma posição bastante discreta e desconfiada em relação ao primeiro presidente civil desde o início da ditadura: 
O discurso de 15 de janeiro traça-lhes o elogio, e não só pelo que significam de tolerância e entendimento: mesmo a participação no Colégio eleitoral foi apresentada, em clara contradição com os fatos, como algo que as multidões teriam exigido das lideranças políticas. [...] a imagem da conciliação e da transição feita sem traumas está tão presente, em sua proposta política, quanto a vontade de mudança que diz expressar. [...]. O que se impõe a verificar, entretanto, é se cumprirá as transformações prometidas no discurso - apesar de todas as nuances verbais que rodearam essa promessa - ou se o conselho de Vargas terminará prevalecendo em seu governo (Folha de São Paulo, O Discurso, 1985, p. 2).

Nota-se com clareza dois pontos importantes: o descontentamento com a participação do Colégio eleitoral nas eleições, denunciando que a vontade popular estaria na contramão dessa escolha; o ceticismo perante as "nuances verbais" de Tancredo Neves. A FSP criticou, então, o caráter dúbio tanto do discurso quanto da figura do presidente escolhido. Na tentativa de se articular pelos interesses de grupos distintos, agradando tanto setores dominantes quanto trabalhadores, - o que para o jornal parece ser uma lição de como fazer campanha populista aprendida com Getúlio Vargas, enquanto ainda seu ministro da Justiça - Tancredo Neves, pela ótica do periódico, se cercou de uma aura de "reserva e indeterminação" (Folha de São Paulo, O Discurso, 1985, p. 2).

Nas páginas do JB, por outro lado, Tancredo Neves foi laudado e entendido como a força necessária para inserir o Brasil "na corrente do liberalismo moderno" (Jornal do Brasil, Perfil, 1985, p. 10). Além do mais, o jornal faz alusão ao caráter conciliatório do presidente eleito. Em referência ao discurso de Tancredo em 15 de janeiro de 1985, o periódico aponta:

Com o banho lustral de democracia que ontem recebemos, plantam-se em nós também a semente de uma nova mentalidade, na qual a idéia do equilíbrio e da conciliação deve substituir para sempre as ilusões de que o excesso de Estado é o esteio da estabilidade (Jornal do Brasil, Perfil, 1985, p. 10).

A expectativa do JB era justamente, como demonstrado pelo adjetivo "equilíbrio", que o novo presidente promovesse o balanceamento e conciliação, assim como uma diminuição da interferência estatal. Se configura, portanto, como uma crítica ao estatismo da ditadura militar e, ao mesmo tempo, uma defesa do estado mínimo. Desse modo, é reforçado a defesa do periódico de uma abertura democrática de caráter negociativo pelas elites políticas e seu repúdio às perspectivas de distensão mais radical promovida por grupos populares. 
É extremamente curioso, no entanto, como a posição do jornal mudaria drasticamente em pouco mais de uma semana, conforme a matéria escrita por Luiz Antonio Villas-Bôas Corrêa ${ }^{17}$, repórter político do jornal:

O presidente eleito Tancredo Neves viajou ontem para uma curta e intensa temporada no exterior, levando na bagagem as especulações sobre o futuro Ministério e as excitadas esperanças sobre planos e projetos do seu governo. Tancredo levou consigo o governo que ainda não começou. [...]. Desse jeito, quando Tancredo chegar ao Palácio não encontrará ninguém. Além, é claro, do Presidente Figueiredo, à espera na rampa, para a entrega da faixa e das chaves. [...]. Em todo o caso, nada de alarmante. Afinal, fomos sendo treinados a não contar com o governo para coisa nenhuma. E, depois, a temporada está boa, com praia, verão, férias e o carnaval a caminho. Dá para aguentar. (Corrêa, 1985, p. 11).

O que é fundamental não reside no fato de tal crítica ter solidez ou não, mas na mera oscilação do jornal e no fim de sua identificação e expectativa positiva em relação ao novo governo - este que nem mesmo chegou a se consolidar por conta da morte de Tancredo Neves antes de sua posse. Essa mudança de postura do JB demonstra a fragilidade e mutabilidade dos apoios e alianças durante o período. No momento em que as esperanças do periódico se esvaziaram, a opinião positiva se converteu em crítica. Considerando o governo de Figueiredo já acabado, sendo o prazo estipulado para a posse do novo presidente apenas um casuísmo, o jornal entende que, neste momento, não há governo algum.

\section{Considerações finais}

As ações de ambos os periódicos, seus apoios e divergências, devem ser concebidas dentro de um contexto de disputa em que a realidade não estava previamente definida, sendo constituída de acordo com a própria dinâmica da prática social. Mesmo a hesitação e oscilação política dos jornais, durante o período ditatorial, indica que, na beirada estreita dos

\footnotetext{
${ }^{17}$ Evidentemente, reconhecemos que existem diferenças entre os diversos tipos de materiais que compõem a fonte jornalística (desde charges, matérias, notícias até editoriais), assim como existe uma variação no espaço de ação dos profissionais que produzem esses documentos. Um editorial, por exemplo, normalmente é a parte do jornal em que os proprietários exercem maior controle; nas charges, por sua vez, o artista geralmente possui um espaço de autonomia maior. Essa autonomia, no entanto, não deve ser supervalorizada. O exemplo de Claudius chargista que trabalhou para o JB até 1966 - demonstra como o jornal poderia agir caso as charges entrassem em discordância com sua linha editorial. Seus desenhos ficaram cada vez mais escassos nas páginas do jornal até que ele saiu da empresa e começou a trabalhar, pouco tempo depois, para o Correio da Manhã, periódico com posição mais crítica em relação à ditadura do que o JB naquele ano (Motta, 2013). Portanto, mesmo reconhecendo suas especificidades, entendemos os artigos assinados como parte de um todo maior: o jornal, que escolhe jornalistas e define linhas editoriais, não podendo ser confundidos os artigos assinados com meros textos de opinião.
} 
acontecimentos, tanto o JB quanto a FSP preocupavam-se em não cair em falência, nem perder legitimidade perante seu público leitor.

Desde o apoio ao Golpe de 1964, por parte da grande imprensa nacional, passando ao seu colaboracionismo durante os anos de chumbo da ditadura, até sua oposição mais direta ao regime a partir da década de 1970, todas essas atitudes devem ser compreendidas sob a perspectiva de que essas empresas jornalísticas possuem também a necessidade de se firmar para reivindicar seus objetivos próprios. Em outras palavras, almejam orientar-se dentro de um contexto político em que os referenciais são mutáveis e que o rumo dos acontecimentos não se baseia em um dado pré-estabelecido. Assim como o Golpe de 1964 não pressupunha a ditadura posterior (no sentido de se definir previamente suas características e variações em cada momento), o conturbado momento de transição não pressupunha, de igual modo, a democracia atingida, em seus limites e possibilidades, sendo estes constituídos pela ação dos sujeitos em sua capacidade de negociação e articulação política em um momento em que os próprios horizontes necessitavam ser construídos.

\section{Referências bibliográficas}

ARBEX, J. Folha de S. Paulo (1984-92). In: Showrnalismo: a notícia como espetáculo. São Paulo: Casa Amarela, 2001, p. 140-172.

BACZKO, B. A imaginação social. In: LEACH, Edmund at al. Anthropos-Homem. Lisboa, Imprensa Nacional/Casa da moeda, 1985.

COELHO, F. As charges e suas potencialidades como fonte histórica. In: ASSOCIAÇÃO NACIONAL DE HISTÓRIA - SEÇÃO MATO GROSSO DO SUL. Anais do encontro da Associação Nacional de História, seção Mato Grosso do Sul. Coxim-MS, 2016. Disponível em:<http://www.encontro2016.ms.anpuh.org/resources/anais/47/1478183576_ARQUIVO_Te xtoCompleto-ANPUH-2016-AsChargesesuasPotencialidadescomoFontesHistoricas.pdf >. Acessado em: 30 jul. 2019.

CRUZ, H. A Cidade do reclame: propaganda e periodismo em São Paulo 1890-1915. Projeto História. São Paulo, PUC-SP, n. 13, p. 81-92, jun. 1996.

CRUZ, H; PEIXOTO, M. Na oficina do historiador: conversas sobre história e imprensa. Projeto História. São Paulo, PUC-SP, n. 35, p. 255-272, dez. 2007.

DIAS, A. O estabelecimento dos fatos: uma análise da Folha de S. Paulo e seus "rastros memoriais" durante o regime militar no Brasil. In: ASSOCIAÇÃO BRASILEIRA DE PESQUISADORES DE HISTÓRIA DA MÍDIA. Artigos. Guarapuava-PR, 2011. Disponível em: <http://www.ufrgs.br/alcar/encontros-nacionais-1/encontros-nacionais/8o-encontro-20111/artigos/O\%20estabelecimento $\% 20 \mathrm{dos} \% 20$ fatos $\% 20$ uma $\% 20$ analise $\% 20 \mathrm{da} \% 20 \mathrm{Folha} \% 20 \mathrm{de}$ 
\%20S.\%20Paulo\%20e\%20seus\%20201 crastros\%20memoriais201d\%20durante\%20o\%20regi me\%20militar\%20no\%20Brasil.pdf/view>. Acessado em: 30 jul. 2019.

FERREIRA, M. A reforma do Jornal do Brasil. In: Abreu; Alzira Alves. A Imprensa em Transição: o jornalismo brasileiro nos anos 50. Rio de Janeiro: Editora FGV, 2008, p. 141155.

FICO, C. Espionagem, polícia política, censura e propaganda. In: FERREIRA, J; DELGADO, L. (orgs.). O Brasil Republicano: O tempo da ditadura: regime militar e os movimentos sociais em fins do século XX. Rio de Janeiro: Civilização Brasileira, 2003, p. 167-205.

_. O Golpe de 1964: momentos decisivos. Rio de Janeiro: Editora FGV, 2014.

_. Rumo à Democracia. In: História do Brasil Contemporâneo. São Paulo: Contexto, 2015. p. 89-123.

KOSELlECK, R. Futuro Passado: contribuição à semântica dos tempos históricos. Trad. Wilma Patrícia Maas e Carlos Almeida Pereira. Rio de Janeiro: Contraponto/Ed. PUC Rio, 2006.

LOHN, R. Transição política no Brasil: a grande imprensa e a institucionalização da "abertura" ao final da ditadura militar (Folha de São Paulo e Isto É, 1974-1985). In: ASSOCIAÇÃO NACIONAL DE HISTÓRIA. Anais Eletrônicos. Florianópolis, 2015. Disponível em: <http://www.snh2015.anpuh.org/resources/anais/39/1434395996_ARQUIVO _ANPUHNacional2015ReinaldoLohn.pdf.> Acessado em: 30 jul. 2019.

MOTTA, R. A Ditadura nas Representações Verbais e Visuais da Grande Imprensa: (19641969). Topoi. Rio de Janeiro, UFRJ, v. 14, n. 26, jan./jul. 2013, p. 62-85.

MUNAKATA, K. O Lugar do Movimento Operário. IV Encontro Regional de História de São Paulo. ANPUH - Movimentos Sociais. Anais... Unesp de Araraquara, 1980.

PIRES, E. Imprensa, Ditadura e Democracia: A construção da auto-imagem dos jornais do Grupo Folha 1978/2004. 132 f. Dissertação (Mestrado em História) - Programa de Estudos PósGraduados em História, Pontifícia Universidade Católica de São Paulo, São Paulo, 2008.

PRADO, L; EARP, F. O "milagre" brasileiro: crescimento acelerado, integração internacional e concentração de renda (1967-1973). In. FERREIRA, J; DELGADO, L. (orgs.). O Brasil Republicano: O tempo da ditadura: regime militar e os movimentos sociais em fins do século XX. Rio de Janeiro: Civilização Brasileira, 2003. p. 207-241.

REIS, D. Ditadura e Democracia no Brasil: do golpe à constituição de 1988. 1. ed. Rio de Janeiro: Zahar, 2014.

SADER, E. Quando Novos Personagens Entraram em Cena: experiências, falas e lutas dos trabalhadores da Grande São Paulo, 1970-1980. Rio de Janeiro: Paz e Terra, 1988.

SANTANA, M. Trabalhadores em movimento: o sindicalismo brasileiro nos anos 1980-1990. In: FERREIRA, J. DELGADO, L. (orgs.). O Brasil Republicano: O tempo da ditadura: regime militar e os movimentos sociais em fins do século XX. Rio de Janeiro: Civilização Brasileira, 2003. p. 283-313. 
SILVA, F. Crise da ditadura militar e o processo de abertura da política no Brasil, 1974-1985. In: FERREIRA, J; DELGADO, L. (orgs.). O Brasil Republicano: O tempo da ditadura: regime militar e os movimentos sociais em fins do século XX. Rio de Janeiro: Civilização Brasileira, 2003, p. 243-282.

WILLIAMS, R. Marxismo e Literatura. Tradução de Waltensir Dutra. Rio de Janeiro: Zahar Editores, 1979.

\section{Fontes Primárias}

- Matérias jornalísticas:

A MELANCÓLICA Apatia. Folha de S. Paulo, São Paulo, 13 de abr. 1977. Primeiro Caderno, ano LVI, n. 17.541, p. 2.

A POSSE, segundo o homem comum. Folha de S. Paulo, São Paulo, 13 de mar. 1974. Primeiro Caderno, ano LIV, n. 16.340, p. 3.

ABRAMO, C. Para onde nos levam. Folha de S. Paulo, São Paulo, 03 de abr. 1984. Primeiro Caderno, ano LXIV, n. 20.089, p. 2.

AS REFORMAS. Folha de S. Paulo, São Paulo, 15 de abr. 1977. Primeiro Caderno, ano LVI, n. 17.543 , p. 2.

ATHAYDE, F. Povo - fenômeno novo. Jornal do Brasil, Rio de Janeiro, 25 de abr. 1984. Primeiro Caderno, ano XCIV, n. 17, p 11.

BAHIA, L. A Sós com o Ato. Folha de S. Paulo, São Paulo, 13 de abr. 1977. Primeiro Caderno, ano LVI, n. 17.541, p. 2.

BRANCO, C. O dia de hoje na cidade sitiada. Jornal do Brasil, Rio de Janeiro, 25 de abr. 1984. Primeiro Caderno, ano XCIV, n. 17, p 2.

CASUÍSMO sem voto. Jornal do Brasil, Rio de Janeiro, 15 de abr. 1977. Primeiro Caderno, ano LXXXVII, n. 7, p 8.

CERCEAMENTO inaceitável. Jornal do Brasil, Rio de Janeiro, 25 de abr. 1984. Primeiro Caderno, ano XCIV, n. 17, p 10.

CONFLITO a compor. Jornal do Brasil, Rio de Janeiro, 01 de abr. 1984. Primeiro Caderno, ano XCIII, n. 269, p 10.

CORRÊA, M. O exagero e as reformas. Jornal do Brasil, Rio de Janeiro, 13 de abr. 1977. Primeiro Caderno, ano LXXXVII, n. 5, p 2.

O governo custa a acabar. Jornal do Brasil, Rio de Janeiro, 26 de abr. 1984. Primeiro Caderno, ano XCIV, n. 18, p 11. 
_. Um governo acabou e o outro ainda não começou. Jornal do Brasil, Rio de Janeiro, 25 de jan. 1985. Primeiro Caderno, ano XCIV, n. 289, p 11.

D’ÁVILA alerta para a onda de boatos. Folha de S. Paulo, São Paulo, 01 de abr. 1975. Primeiro Caderno, ano LV, n. 16.821, p. 3.

DIA da decisão. Jornal do Brasil, Rio de Janeiro, 25 de abr. 1984. Primeiro Caderno, ano XCIV, n. 17, p 10.

ELOQUÊNCIA dos Números. Jornal do Brasil, Rio de Janeiro, 26 de abr. 1984. Primeiro Caderno, ano XCIV, n. 18, p 10

FAZENDEIRO do nada. Jornal do Brasil, Rio de Janeiro, 20 de jun. 1984. Primeiro Caderno, ano XCIV, n. 73, p 10.

GREVE pela greve. Jornal do Brasil, Rio de Janeiro, 20 de mar. 1978. Primeiro Caderno, ano LXXXVII, n. 342, p 10.

IMPRUDÊNCIA radical. Jornal do Brasil, Rio de Janeiro, 25 de abr. 1984. Primeiro Caderno, ano XCIV, n. 17, p 10.

INTERESSES convergentes". Jornal do Brasil, Rio de Janeiro, 10 de jun. 1984. Primeiro Caderno, ano XCIV, n. 181, p 10.

LÓGICA da violência. Jornal do Brasil, Rio de Janeiro, 05 de jun. 1984. Primeiro Caderno, ano XCIV, n. 58, p 10.

MDB critica apoio à censura. Folha de S. Paulo, São Paulo, 15 de abr. 1975. Primeiro Caderno, ano LV, n. 16.835 , p. 3

MOTA, C. O presidente Figueiredo e a retomada da abertura. Folha de S. Paulo, São Paulo, 01 de abr. 1984. Primeiro Caderno, ano LXIV, n. 20.087, p. 3.

O DISCURSO de Tancredo. Folha de S. Paulo, São Paulo, 17 de jan. 1985. Primeiro Caderno, ano LXIV, n. 20.378, p. 2.

O DISCURSO do Presidente. MOTA, C. O presidente Figueiredo e a retomada da abertura. Folha de S. Paulo, São Paulo, 01 de abr. 1984. Primeiro Caderno, ano LXIV, n. 20.087, p. 2.

O NOVO governo. Folha de S. Paulo, São Paulo, 14 de mar. 1974. Primeiro Caderno, ano LIV, n. 16.339, p. 2.

PANELA de pressão. Folha de S. Paulo, São Paulo, 17 de mar. 1978. Primeiro Caderno, ano LVII, n. 17.880, p. 2.

PATERNALISMO discutível. Jornal do Brasil, Rio de Janeiro, 19 de mar. 1977. Primeiro Caderno, ano LXXXVI, n. 340, p 10.

PERANTE a História. Folha de S. Paulo, São Paulo, 13 de mar. 1977. Primeiro Caderno, ano LVI, n. 17.510, p. 2. 
PERFIL liberal. Jornal do Brasil, Rio de Janeiro, 16 de jan. 1985. Primeiro Caderno, ano XCIV, n. 281, p 10.

POSIÇÃO contra dissídio. Folha de S. Paulo, São Paulo, 13 de mar. 1978. Primeiro Caderno, ano LVII, n. 17.876, p. 9.

QUEM paga. Jornal do Brasil, Rio de Janeiro, 13 de mar. 1978. Primeiro Caderno, ano LXXXVII, n. 339, p 10.

RÁDIO JB vai à Justiça contra censura. Jornal do Brasil, Rio de Janeiro, 25 de abr. 1984. Primeiro Caderno, ano XCIV, n. 17, p 1.

SER sinônimo de oposição. Folha de S. Paulo, São Paulo, 25 de abr. 1977. Primeiro Caderno, ano LVI, n. 17.554, p. 2.

SILVA, J. Polícia só expulsa $20 \%$ dos seus homens que matam. Jornal do Brasil, Rio de Janeiro, 16 de jan. 1983. Primeiro Caderno, ano XCII, n. 281, p 18.

SINAL de maturidade. Rio de Janeiro: Jornal do Brasil, Rio de Janeiro, 27 de abr. 1984. Primeiro Caderno, ano XCIV, n. 19, p 10.

ULYSSES: extinção contraria distensão. Folha de S. Paulo, São Paulo, 14 de mar. 1975. Primeiro Caderno, ano LV, n. 16.803, p. 5.

UM ESTADISTA. Folha de S. Paulo, São Paulo, 01 de jan. 1975. Primeiro Caderno, ano LIV, n. 16.731 , p. 5 .

UM ESTRANHO pacote. Folha de S. Paulo, São Paulo, 14 de abr. 1977. Primeiro Caderno, ano LVI, n. 17.542, p. 2

UM-TRINTA e seis avos. Folha de S. Paulo, São Paulo, 14 de abr. 1977. Primeiro Caderno, ano LVI, n. 17.542, p. 2

VONTADE dividida. Jornal do Brasil, Rio de Janeiro, 12 de jun. 1984. Primeiro Caderno, ano XCIV, n. 65, p 10. 